\title{
Monetary Condition Index with Time Varying Weights: An Application to Turkish Data
}

\author{
İlyas Şıklar \\ Anadolu University, Faculty of Economics and Administrative Sciences \\ Department of Economics \\ E-mail: isiklar@anadolu.edu.tr \\ Burhan Doğan \\ Anadolu University, Faculty of Economics and Administrative Sciences \\ Department of Economics \\ E-mail: burhand@anadolu.edu.tr
}

Received: January 16, 2015 Accepted: March 7, 2015

doi:10.5296/ber.v5i1.7101 URL: http://dx.doi.org/10.5296/ber.v5i1.7101

\begin{abstract}
In this study, the evaluation of the impact of the fluctuations in interest rate and exchange rates on monetary policy is carried out through the use of Monetary Conditions Index (MCI). The weights for construction of MCI are derived using the time varying framework with Kalman Filter algorithm. Despite the simplifying assumptions made during its construction, the time varying version of MCI provides opportunities for the analysis of the contribution of the monetary conditions to the evaluation of Turkish economy, especially in recent past when it is compared to traditional constant weighted MCIs. According to the fundamental result obtained in the study, the changes in inflation give rise to changes in both interest rates and exchange rates. Moreover, the result obtained also demonstrates that the interest rate channel, when compared to exchange rate channel, have a stronger and more rapid impact on the transfer of the changes in policies to economy.
\end{abstract}

Keywords: Monetary policy, Interest rate, Exchange rate, Monetary conditions index, Kalman filter algorithm. 


\section{Introduction}

Monetary policy generally affects economic conditions such as inflation and aggregate output through many ways known as the transmission mechanism. Sudden changes in political tools cause changes in investment, saving and spending habits of consumers and investors through interest rate. Likewise, differentiation of the value of the exchange rate together with sudden change in monetary policy cause change in import and export data. Occurrence of such facts in tandem may cause some effects on aggregate demand, aggregate output and prices by the way of consumption, investment and net export. Because the effect of interest rate and exchange rate channel on economic conditions is high, an index providing weighted mean has been generated. Such an index known as monetary condition index (MCI) can be defined as weighted mean of changes in exchange rate and interest rate dependently values of them in a basic period (Batini and Turnbull, 2002). Because of the importance of both variables in monetary transmission, MCI shows changes in short run interest rate and exchange rate as a single variable. Thus influence degrees of interest rate and exchange rate on aggregate demand and general price level can be determined by calculating the MCI.

MCIs are motivated in terms of standard Keynesian open economy characterized by aggregate demand among which real interest rate and real exchange rate are as a function in others (Bayangos, 2000, pp 6). Because influences of interest rate and exchange rate on the economy change according to magnitude and openness of the economy, MCI measurements calculated in various countries may differ. In small open economies, monetary policy may be quite effective on general level of aggregate output and prices through interest and exchange rate. Increasing the cost of financial capital out of productive factors by high interest rates may cause decreases at the level of aggregate output. This case may generally cause appreciation of local currency while other conditions are constant. The appreciated local currency will cause decrease in net export and decrease in domestic production (Korhonen, 2002, pp 4). Because of this interaction monetary authorities in the small open economies may frequently utilize interest and exchange rate tools in order to be effective on output and prices. By finding weighted mean of interest rate and exchange rate within the MCI, interventions of monetary authorities to aggregate demand and prices may be made more effective. Therefore, a central bank can optimize its objective function through the regulation of weighted average comprised of exchange rate and interest rate in accordance with the existing macroeconomic conditions in the country (Gerlach and Smets, 2000). MCI can be used as the monetary indicator of inflation targeting monetary policy. Such an indicator shows whether central banks loosen or tighten monetary policy. For this reason MCI as a monetary policy indicator has an important role as operational target in conducting the monetary policy (Freedman, 1995). Occurrence of an increase in MCI indicator signals that there is a tightening in monetary policy and a decrease in MCI indicator signals a loosening in monetary policy. Since most of the studies in the literature have obtained MCI as 2:1, a change in exchange rate by $2 \%$ and a bustle in interest rates by $1 \%$ causes an equivalent effect on aggregate demand and prices (Brash, 1997). Hence we can generate following table: 


\begin{tabular}{|l|l|l|l|}
\hline Exchange rate & Interest rate & MCI & Monetary Policy \\
\hline Increase & Increase & Increase & Tight \\
\hline Increase & No change & Increase & Tight \\
\hline No change & Increase & Increase & Tight \\
\hline Very little decrease & Increase & Increase & Tight \\
\hline Decrease & Decrease & Decrease & Loose \\
\hline Increase & Decrease & Decrease & Loose \\
\hline Decrease & No change & Decrease & Loose \\
\hline No change & Decrease & Decrease & Loose \\
\hline
\end{tabular}

In this study, MCI calculation is carried out as to include the years of $1991-2013$ in monthly basis. In calculation of MCI, almost all studies concerning Turkey have been carried out by using constant weights for interest rate and exchange rate variables as common in the literature. However, this study differs by using the time varying coefficients for the mentioned variables in construction process of MCI for the period under investigation. Through the calculation of MCI with the time varying coefficients in Turkey, opportunity for being able to see influence levels of monetary authorities, institutions and corporates on changes in monetary policies will be more easily provided. In the first part, MCI studies carried out all around the world are included and differences between countries are presented. In the second part, information about limits and reasons of the model to be applied will be given. In the third part, results are interpreted by carrying out empirical analysis. In the last part, study is going to be summarized and evaluated in general terms and empirical results.

\section{Literature}

Today, as an indicator of monetary policy conditions, MCI is measured by central banks and various institutions of many countries (Neil R. Ericcson et al., 1998, pp 1). Today, calculated MCI values that are used as an indicator of monetary policy under the leadership of Central Bank of Canada are published by central banks, public institutions and companies (Gerlach and Smets, 2000, pp 1680). Whereas MCI is calculated by institutions such as OECD, IMF in addition to central banks in order to evaluate monetary policy, companies such as Deutsche Bank, Goldman Sachs, JP Morgan and Merrill Lynch have published MCI for the purpose of investigating monetary conditions in many countries (Ericsson et al., 1998, pp 2).

When we look at previous studies concerning with MCI, some of the remarkable studies conducted are Duguay (1994) for Canada, De-Simone, Dennis, and Redwards (1996) for New Zealand, Jore (1994) for Norway. Since 1990, Canadian Central Bank has been using MCI updated monthly as operational target instead of monetary aggregates. Structure of MCI generated by Canadian Central Bank was based on quarterly output estimations of Duguay (1994) covering the period of 1980-1990. Short-term real and nominal MCI was estimated through independent variables including real exchange rate, real interest rate and real output. In the mentioned study, whereas changes in interest rates affect aggregate demand by 3\%, changes in exchange rates affect $1 \%$. MCI for New Zealand was based on a model generated by De-Simone, Dennis, and Redwards (1996) including 1987-1995 period. New Zealand Central 
Bank has used real interest rate and real exchange rate as independent variables and real output as dependent variable. MCI generated for Norwegian Central Bank was based on aggregate demand model with single-equation by using quarterly data for the period 1985-1994. When we look at the results obtained in this study, MCI weights are 2:1(Eika et al., 1996).

Frochen (1996) has generated monetary condition index for five European countries (France, Germany, Spain, England, Italy) with the series including nominal short and long term interest rates and effective exchange rate. Indicators showed that monetary policy may have a balancing effect on price level in France and Germany since 1990. Hataiseree (1998), in his study regarding Thailand, indicated that usage of MCI index presents a positive image as an important indicator for characterizing short term monetary conditions in conducting monetary policy as well as evaluating the behavior of inflation rate. However, he draw attention that further investigations are required for being able to guide monetary policy under floating exchange rate regime that would occur in future. The empirical analysis carried out in this study demonstrates the relative significance of exchange rate and interest rate variables in the construction of MCI. It is particularly underlined that the use of MCI in the evaluation of economic and monetary conditions in Thailand is more effective compared to the use of exchange rate or interest rate individually. The study includes the empirical analysis of the relationship between inflation rate and MCI for Thailand economy. Empirical results show that there is a high correlation between general evolvement of MCI and inflation. Another important reflection of this finding for conducting monetary policy is that emergence of MCI is a useful indicator for monetary conditions in the short term and can be used for affecting oncoming evolvements of inflation (Hataiseree, 1998, pp 13).

Kesriyeli and Koçaker (1999) have generated weights through estimation of price equation rather than aggregate demand equation due to being impetus of exchange rate in price regulation process in Turkey. Moreover, weights in MCI are stated as to reflect the 'link' between operational target and final target. Gerlach and Smets (2000) have generated a theoretical model showing that monetary condition index may have been written in the aspect of suitable feedback rule of central bank. They estimated reaction functions of central banks to changes in exchange rate by targeting inflation for Australia, Canada and New Zealand. Whereas the central banks of New Zealand and Canada using the MCI as operational target react to changes in exchange rate potently, Australian central bank does not.

Korhonen (2002) estimated monetary transmission mechanism in three European Union candidate countries (Czech Republic, Poland and Slovakia). MCI including exchange rate which has very little effect on Slovak economy bewilderingly was calculated. While MCI generated for Czech Republic in the study produces quite similar results with small EU countries, Poland seems extremely sensitive to exchange rate changes.

Siklos (2002) mentions advantages and disadvantages of MCIs. He indicated that while generated MCI may increase credibility of monetary policy, a central bank's close reaction to each change in MCI may cause confusion among financial market participants. Advantages and disadvantages of MCI are also mentioned by Kaytanc1 (2008). She points out that the usage of a model including unnecessary externality assumptions and consisting of non-stationary 
parameters in the assessment of monetary policy may be misleading.

In the study carried out by Hyder and Khan (2006) weights for construction of MCI are obtained by using Johansen's cointegration technique. Obtained MCI shows that there were 6 loosing periods and 8 tightening periods in terms of monetary conditions in Pakistan between March 1991 and April 2006. Knedlik (2006) utilized MCI to evaluate the optimality of the monetary policy in South Africa. Gan (2008) estimated comparative effects of exchange rate and interest rate on output gap by using weights of real exchange rate and real interest rate in the estimation of optimal monetary policy.

\section{Generating MCI}

In order to be able to generate monetary condition index various econometric techniques can be used. As observed in previous studies, measurement of MCI has been handled in two aspects. According to this, MCI can be established by taking into account the impact of changes in interest rate and exchange rate on the "aggregate demand" or "price level". In the first case, the weights used for the construction of MCI are obtained through the prediction of aggregate demand equation. Whereas in the second case, the impact of changes in exchange rate and interest rate on prices is analyzed. In this case, the weight of exchange rate on MCI is bigger because of its direct impact on the prices in addition to its indirect impact resulting from the aggregate demand (Kesriyeli and Koçaker, 1999, pp 3). It should be noted that such measurements can be carried out through nominal and real values (Freedman, 1995).

\subsection{Methods}

When we look at first studies carried out about MCI in the literature, models based on methods with single equation are used, however in the studies carried out recent years empirical analysis are carried out through using multi equation models. Furthermore, by using structural VAR models, MCI can be generated without any necessity for restrictions used in other simultaneous equations (Tar1 and Bozkurt, 2006, pp 4-5). As the value of MCI at time $t$ is defined as the weighted sum of the changes in exchange rate and interest rate in the selected base year, the formula to be used in the calculation of MCI can be written as follows:

$$
M C I_{t}=w_{I R}\left[I R_{t}-I R_{b}\right]+w_{E R}\left[\log \left(E R_{t}\right)-\log \left(E R_{b}\right)\right]
$$

In this equation, $I R_{t}$ and $E R_{t}$ refer respectively to interest rate and exchange rate at time $t . I R_{b}$ and $E R_{b}$ are the interest rate and exchange rate in the selected base year, respectively. The most important factor in the formation of this equation is the value of weights $\left(w_{s}\right)$, since the value of the weights in question demonstrates the relative significance of exchange rate and interest rate in respect of impacting the final objective either in the form of inflation or output level. The weighing of the two variables in the construction of MCI is possible through the use of various econometric techniques. Among these techniques, the most frequently used are: $(i)$ approach based on the use of a single equation in relation with either the price level or output level, (ii) approach based on trade elasticities, (iii) approach based on Vector Autoregressive (VAR) and Johansen cointegration models. As discussed in the final section, the use of VAR and Johansen cointegration models is more preferable considering the shortcomings associated with the first 
two approaches. The shortcomings mentioned include omitted variable bias, dynamic exogenity and feedback problems. The cointegration methodology is the generally preferred approach as it takes the aforementioned problems in consideration.

\subsection{Restrictions}

Although MCI can serve as an important indicator of monetary conditions, usage of MCI as an operational tool is restricted because selection of weights for interest rate and exchange rate depends on its relative effect on inflation and aggregate demand. Other restrictive factors are that MCI does not prevail on market expectations on policies and selection of variables of MCI may change. Such kind of reasons restricts usage of MCI as a monetary condition indicator (Hyder and Khan, 2006). Usage of MCI as an operating target in monetary policy is found inconvenient due to extreme changes in its components. In some countries (Canada, New Zealand etc.), MCI is used as operating target in conducting monetary policy whereas in some countries (Norway and Sweden) there are restrictions on its usage as a target in monetary policy design (Neil R. Ericsson et al., 1998).

If interest rates and buying rate of exchange are completely controlled by monetary authority, the importance of monetary conditions would become relatively simple. In practice, as Kennedy and Van Riet (1995) state, differentiation of these variables highly depends on reaction of the market for expected monetary policy stance.

Since the beginning of 1990, whereas central banks have estimated monetary condition index as either an operating target of monetary policy or an indicator of monetary conditions, it is observed that problems with MCI estimation have been increasing. For that reason, when we want to evaluate effects of monetary policy on the economy, we should evaluate the links between economic fundamentals and external factors like exchange rate (Stevens, 1998). When we consider such kind of factors, it is suggested that MCI should not be used alone and other channels and effects of lags should not be neglected in designing monetary policy toward specified targets like inflation (Svensson, 1998).

\section{Constructing the MCI For Turkey}

As it was previously pointed out by the authors of the cited works, the construction of monetary conditions index is not an easy task, since such a variable not only needs to reflect the current developments in financial markets but also to constitute a meaningful indicator in relation with the future economic activities. Furthermore, a correctly predicted monetary conditions index is also expected to "provide a continuously updated flow of information on the future whereas the traditional economic predictions are updated on a monthly or quarterly basis" (Mayes and Viren, 2001, pp 8).

Generally speaking, MCI is an indicator which provides information on the current inflation and monetary policy in a given country. Nevertheless, as Grande (1997) points out, how the required information will be obtained from a composite indicator does not constitute the only problem. The additional assumptions required in order to put this indicator in practice constitute another problem. In this section, we are going to construct an indicator with above-mentioned characteristics. 


\section{Mll Macrothink}

Business and Economic Research

ISSN 2162-4860

2015, Vol. 5, No. 1

The first stage in the analysis is the creation of an aggregate measure for MCI. Following Goodhard and Hofmann (2001), we will develop our analysis within the context of two assets model, namely short-term interest rate and real effective exchange rate. In this part, we are going to explain how MCI is derived and especially how it is used in the formulation of monetary policy. The first problem in relation with the construction of MCI is the determination of weights in relation with each asset. Goodhard and Hoffman (2001) suggest three different approaches in this regard: the estimation of a large-scale macro econometric model, the estimation of an equation system consisting of reduced form aggregate demand and aggregate supply functions and the analysis of impulse response functions obtained through VAR model estimation. The authors mentioned make a reference to the difficulties posed by the first model and conclude that the preference of the second and third methods would be more appropriate. The two methods offer similar results except for Germany and England. However, a common problem for the two proposed methods attracts attention: despite the size of the sample used, the weights used in relation with each financial variable are fixed. As a matter of fact, the portfolios of firms and households tend to change in relation with business cycle and the emergence of certain events in the economy. In this study, we will try to overcome this problem by proposing an alternative for the calculation of weights in relation with each variable. In order to consider the changes manifested by the weights over time, what we propose is the use of Kalman filter algorithm.

Taking into consideration the contributions made by Eika et al.(1997), Mayes and Viren (1998), Goodhard (2000), Goodhard and Hofmann (2001) and Mayes and Viren (2001) we are going to formulate a formal model which demonstrates the importance of financial variables in the implementation of monetary policy. By this means, we can form a simple model corresponding to the traditional backward looking aggregate demand - aggregate supply model which has been enhanced to include assets market (Goodhard and Hofmann, 2001):

$$
\begin{gathered}
\pi_{t}=\phi_{1}+\sum_{i=1}^{k_{1}} \phi_{1, i} \pi_{t-i}+\sum_{j=1}^{k_{2}} \phi_{2, j} y_{t-j}+\eta_{t} \\
y_{t}=\beta_{1}+\sum_{i=1}^{g_{1}} \beta_{1, i} y_{t-i}+\sum_{j=1}^{g_{2}} \beta_{2, j} r i_{t-j}+\sum_{l=1}^{g_{3}} \beta_{3, l} r e_{t-l}+\mu_{t}
\end{gathered}
$$

Where $\pi_{t}$ refers to inflation and is calculated as $100 \times\left[\ln \left(C P I_{t} / C P I_{t-12}\right)\right]$ while $y_{t}$, reflecting the output gap, is the gap between the actual and potential output and is calculated as percentage deviation of natural logarithm of monthly industrial production index from its Hodrick-Prescott trend. The financial markets are represented by two variables: $r i$ and $r e$. These variables reflect respectively the gap between the real and potential interest rate and the real effective exchange rate. Long term values of asset prices have been calculated through the use of Hodrick-Prescott filtering technique. For the selection of sample, the necessity to cover the principal events causing changes in government and monetary policies was taken as basis. In this case, the period between January 1991 and December 2013, during which fundamental transformations and changes occurred in terms of politics and economic policy, was selected and 276 observations on a monthly basis were included. 


\section{Macrothink

The construction of MCI was divided into two phases: the first phase covers the estimation of Equation 2 through the use of Kalman filter algorithm, whereas the second phase includes the definition of composite index to be formed by using coefficients which change depending on time. For the purposes of the analysis in this study, the most important point is the values of the coefficients in Equation 2. Therefore, in order to understand the potential significance of an unobservable change in $\beta_{i, t}$, the estimation of Equation 2 in state space form is required. Consequently, Equation 2 can be rewritten in state space form as follows:

$$
\begin{aligned}
& y_{t}=Z^{\prime} \beta_{t}+\mu_{t} \quad \text { (transition equation) } \\
& \beta_{t}=F \beta_{t-1}+\eta_{t} \quad \text { (measurement equation) }
\end{aligned}
$$

In these equations, $Z$ reflects a ( $T x k$ ) dimension matrix containing all the explanatory variables and a constant term, whereas $y_{t}$ reflects the value of output gap, as explained above. On the other hand, $\beta_{t}$ is $(k x l)$ dimension state vector covering all the slope coefficients which change over time. The $(k x k)$ dimension $F$ matrix contains the autoregressive coefficients of $\beta_{t}$. By doing so, we allow the coefficient $\beta_{t}$ to follow random walk process. It is assumed that the error terms are independent white noise and $\operatorname{Var}\left(\mu_{t}\right)=Q$;

$\operatorname{Var}\left(\eta_{s}\right)=R ; \quad \operatorname{Var}\left(\mu \eta_{s}\right)=0$ for all $t$ and $s$

By stating Equation 2 as above, the estimation of state vector for $t=k+1 ; k+2 ; \ldots T$ through the use of Kalman filter is made possible. Considering the purposes of our analysis, this algorithm enables us to observe the dynamics of the iteration between the economic activity gap and the variables which explain this gap. This technique is effective even in cases where we suspect a structural break in the estimation period but are not sure of its exact date. In fact, this recursive technique is the calculation of the linear least squares of the estimated state vector when the observation at time $t$ is as given. Whereas the initial value of state coefficient estimated by OLS is given, the state coefficient of each term is updated on the basis of inflation in the previous terms by making use of this technique. Therefore, likelihood function is maximized until reaching convergence value. The following equations are recursively estimated to obtain state vector $\beta_{t}$ and its mean squared error $P=\left\lfloor\left(\beta_{t}-\hat{\beta}_{t}\right)\left(\beta_{t}-\hat{\beta}_{t-1}\right)\right]$ :

$$
\beta_{t \mid t}=F \beta_{t \mid t-1}+H_{t-1} Z\left(Z^{\prime} H_{t-1} Z+Q\right)^{-1}\left(y_{t-1}-Z^{\prime} F \beta_{t-1 \mid t-1}\right)
$$

and

$$
P_{t \mid t}=H_{t-1}-H_{t-1} Z\left(Z^{\prime} H_{t-1} Z+Q\right)^{-1} Z H_{t-1}
$$

Where $H_{t}$ is defined as $F P_{t-1 / k-1} F^{\prime} R$ and $\beta_{t+1 / t}$ is the estimation of state vector for $t+1$ period based on the information at time $t$. 


\section{Macrothink}

The methodology summarized above provides an opportunity for removing the problems resulting from an unobservable factor affecting the output gap. Therefore, it is possible to observe the change of asset price weight over time for each endogenous variable in the model.

The second phase consists of the calculation of the weight of each asset within MCI. The equation to be used to this end has been given below:

$$
\text { weight of } X_{i, t}=\frac{\text { coefficien } t \text { value of } X_{i, t}}{\sum_{t=1}^{n} \text { coefficien } t \text { value of all assets }}=W_{i, t}
$$

Here, $X_{i, t}$ is the price of asset $i$ at time $t$, whereas $n$ reflects the size of the sample. Weights which change over time as calculated through the use of above equation have been set out in Figure 1.

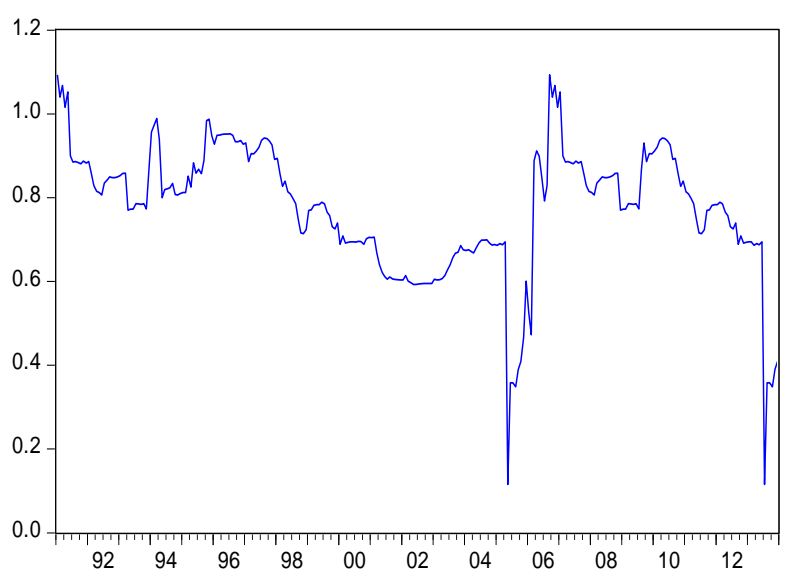

Weights for real interest rate

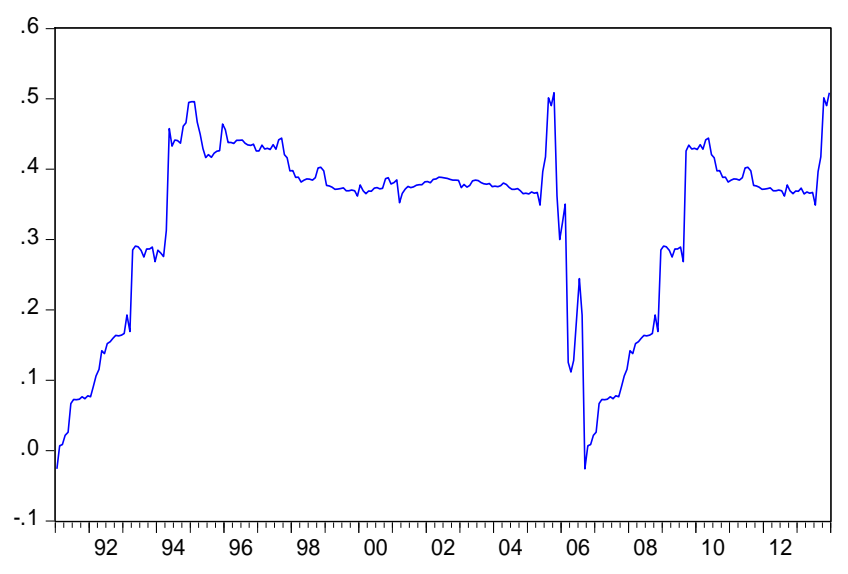

Weights for real exchange rate

Figure 1. Weights Estimated for Calculation of the MCI

The last phase in the calculations is the definition of MCI:

$$
M C I_{t}=\sum_{t=1}^{n}\left(W_{i, t}\right)\left(r i_{t}+r e_{t}\right)
$$

According to this equation, the increase in MCI means the tightening of monetary conditions. The Figure 2 below shows the MCI values for Turkey calculated through time varying weights as basis. The calculated MCI fluctuates between dramatically different ranges. Taken as a whole, MCI can be said to fluctuate around (-1) throughout the period under consideration. Moreover, the volatility of MCI is observed to have increased especially between the years 2000 and 2003 as well as 2007 and 2009. 


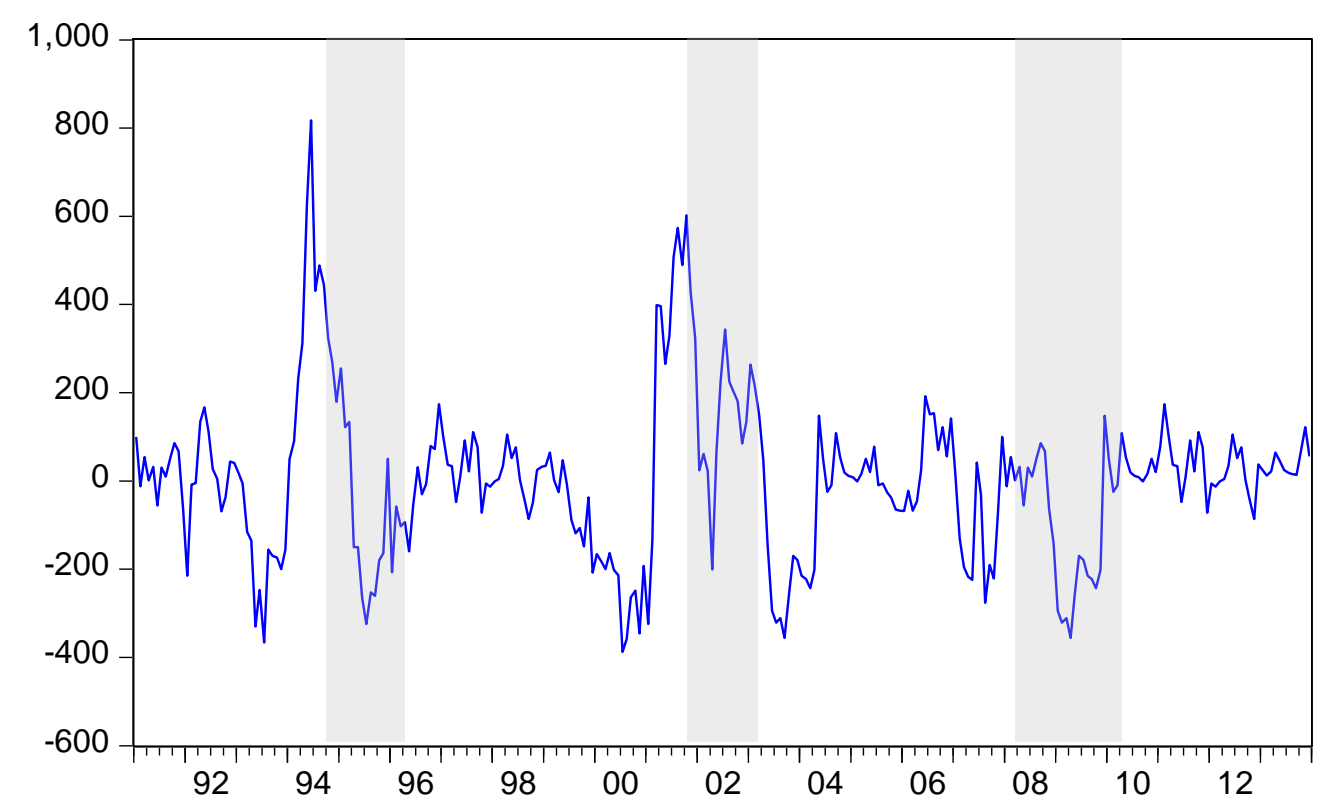

Figure 2. MCI in Turkish Economy

Turkey faced a chronic and increasing inflation problem beginning from the 1970's up until the end of 1990's. During this period, the monetary policy was changed frequently and after 1990, the monetary policy implemented in Turkey targeted the real exchange rate. In this period, nominal exchange rate lost value in accordance with inflation to maintain real exchange rate fixed and ensure the competitiveness of Turkish exporters. Nevertheless, the policies implemented are not transparent. Frequent changes in policies and lack of transparency in exchange rate policies brought about a significant loss of credibility for Central Bank of the Republic of Turkey (CBRT). For instance due to huge budget and current account deficits in 1994, domestic currency had been devaluated almost 60 percent against US Dollar. The shaded area in Figure 2 depicts the tightening monetary conditions before 1994 twin deficits crisis in Turkey. On the other hand, Turkey faced a rapid financial outflow in November 2000 as foreign investors' loss of trust. After the obstacles before the capital flow were removed in 1990, the underdeveloped financial system was left vulnerable against speculative attacks. The financial outflows mentioned resulted in a domestic banking crisis and emergence of a vast budget deficit, which in turn paved the way for a rapid monetary expansion, increasing inflation and rapidly depreciating national currency. The second shaded area in Figure 2 shows the unbearable tightening of monetary conditions before February 2001. As the exchange rate target became unsustainable, the domestic currency was left for fluctuation. In the post-crisis era, reforms aiming at restructuring Turkish economy were enforced. In addition to transition to floating exchange rate regime, institutional reforms aiming at increasing the role of the markets, restructuring public banks and decreasing the influence of public sector on the economy were implemented. One of the most important reforms enforced during this period is the legal amendment which has enabled the Central Bank to enforce an independent monetary policy. Thanks to this reform, prerequisites for transition to a monetary policy aimed at inflation targeting were provided. The process of transition to inflation targeting began in 2002 and ended in 2006. After this, the official monetary policy of Turkey was transformed to 
inflation targeting regime. Another objective of the structural reforms implemented was to accelerate the harmonization of Turkish economy with European Union standards.

The transition to floating exchange rate regime in Turkey decreased the impact of exchange rate pass-through to prices to a great extent and weakened the issue of dollarization. It is possible to assert that this change in exchange rate policy was reflected positively in the effectiveness of monetary policy. On the other hand, considering that Turkey is a small open economy, the transition to floating exchange rate regime caused a change in monetary transmission mechanism by strengthening interest rate and credit channels as well as weakening the effect of exchange rate pass-through. This transformation is also supported by the economic theory. According to the theory, flexible foreign exchange rate regime provides public administration with opportunities in taking the necessary measures for tackling domestic problems such as domestic shocks and to implement a flexible monetary policy (Calvo and Mishkin, 2003).

As a part of 2001 reforms, CBRT obtained instrument independence and thus was freed from the impact of political decisions and choices. In addition, through the legal amendments enforced, accrediting public sector (including the Treasury) came to an end. The reforms implemented transformed the fundamental interest of CBRT to shaping the expectations in the short run and this policy paved the way for the strengthening of interest rate channel in monetary transmission mechanism.

Another aspect of the structural reform process implemented in Turkey was the restructuring of public banks. Ineffectual branches were closed and their employees were eliminated through distribution to other institutions, capital adequacy ratios were increased and a new institution entitled Banking Regulation and Supervision Agency (BDDK), which was responsible from supervision of all the banks, was established. In a similar vein, reforms were implemented in other public institutions for harmonization with European Union. These reforms included the elimination of ineffectual units and positions in public sector, reformation of agricultural support system, limitation of employment in public institutions, ensuring the budget discipline in public sector and introduction of new regulations with regard to accountability. Through the new laws enforced and the amendments on the existing laws, changes were introduced with regard to regulation and supervision of private sector with the aim of increasing competition and economic efficiency.

In the 5 years following the reforms, the annual economic growth rate increased to $7 \%$ on average and inflation decreased to single digit levels. A substantial improvement was achieved in public sector indebtness and foreign debts of the country. Airado et al. $(2004,1)$ note that "the assessment of both private market actors as well as of international institutions is that the program has been successful in re-establishing macroeconomic stability, reducing the debt ratio and laying the ground for a durable acceleration of growth in an environment of drastically reduced inflation and much lower real interest rates."

New conjuncture which emerged after the global crisis has lead central banks to search for alternative policies. In this context, from the end of 2010, the Turkish Central Bank (CBRT) has also designed and implemented a new monetary policy framework. One of the important 
lessons from the global crisis, while focusing on the price stability, central banks should not overlook accumulated risks and puffiness of asset prices in financial system. In this respect, the view which central banks should give more importance to the opinion of the financial stability such as the international platforms of the G-20 is increasingly widespread. Also, in order to prevent financial crises the importance of works which referring reaction with macro policies in recent economic literature gradually gained value (Bianchi and Mendoza 2011, Jeanne and Korinek, 2010).

Beside varying approaches about changes in economic policies and central banks, the extraordinary global economic conjuncture has also been a significant share with CBRT's new policy search. Damages caused by intense crisis resulting from Lehman Brothers' bankruptcy in September 2008 and relating policies applied by the developed countries have brought the unusual dynamics with along. Although five years after the crisis period, correction period of balance sheet which started in developed countries after crisis is still continuing. Especially in developed countries balance sheets of the public sector and the banking system were entering in a negative mutual interaction and this leads to slowing the recovery period. This circumstance also forces the limits of central banking.

From mid-2009 while Turkey's economy has entered the process of rapid growth related to domestic demand, recovery with main trade partners has been much slower. In other words, during this period, it was observed that the internal and external demand were in serious decomposition. Especially trend even became more evident by increased short term capital flows after the second quantitative expansion packs applied by the central banks of developed countries in 2010. While capital inflows brought along excessive increase in value of Turkish Lira, at the same time use of domestic credit has also been accelerated. As a result of these developments, a serious distortion was observed in the balance of foreign trade and the current account. During this period, because of the increase in the current account deficit and capital inflows-quality degradation, economy has become brittle against sudden changes in global risk trap. As of the last quarter of 2010, it has been observed that almost the entire current account deficit was financed by short-term capital and portfolio investments. While looking at Turkey in particular with historical movements, it has been realized that fluctuation in capital streams has been playing an important role on macroeconomic stability.

Current account deficit has been progressed in high levels due to the demographic factors and other structural reasons, and this might affect the economy to be become more brittle against fluctuations in capital movements. Limiting the current account deficit to a great extent (cyclic portion of) and balancing the external funding are being important in order to have macroeconomic stability and sustainable growth. In 1994, 2001 and 2008 crises hard narrowing in economic activity has always become along sudden cease in capital flows. This observation signs that the durability of the economy against sudden changes in global risk trap should be increased in a conjuncture with fairly short term and fluctuating financing; at the same time it reveals the importance of a more flexible approach to monetary policy (Kara, 2012). 


\section{Conclusion}

This study evaluates the stance of monetary policy through the use of MCI and discusses how interest rate and exchange rate can be taken into account at the same time. In different policy analyses recommended, there is a common problem: Despite the size of the sample, the weights of financial variables which are used during the construction of MCI are fixed. However, change of portfolios of the companies and households together with the business cycle and certain economic events is an expected reaction. In order to overcome this problem, an alternative methodology for the calculation of the weight of each asset is recommended in this study. In order to determine the changes of weights over time, the use of Kalman filter algorithm is the suggested. Financial markets were included in the model with two variables through the consideration of the traditional backward looking aggregate demand - aggregate supply model which has been enhanced to include assets market: real interest rate and real exchange rate. These variables were respectively represented through the use of the gap between real and potential interest rate and real effective exchange rate; long term values in relation with asset prices have been calculated through the use of Hodrick-Prescott filtering technique. For the selection of sample to constitute the basis for the study, the necessity to cover the principal periods involving fundamental changes in public and monetary policy was taken as basis and subsequently the period between January 1991 and December 2013 was selected.

The construction of MCI was divided into two phases: the first phase included the estimation of aggregate demand and aggregate supply functions through the use of Kalman filtering algorithm, whereas the second phase included the formation of composite index by using coefficients which change over time. The method used enables the determination of the impacts of unobservable factors likely to influence output gap. Therefore, it is possible to observe the change of asset price weight over time for each endogenous variable. MCI was established by using the estimated weights for interest rate and exchange rate which vary over time and the tendencies throughout the period were analyzed. Taken as a whole, MCI can be said to fluctuate around (-1) throughout the period covered. On the other hand, the increase in the volatility of the index during the periods covering the years 2000-2003 and 2007-2009 attracts attention. The fundamental finding of the empirical analysis carried out in this study is that the relative significance of interest rate as the determinant of monetary conditions is higher compared to exchange rate. Such a finding strengthens the ability of the central bank with regard to the determination of policy stance. In addition, the use MCI in the evaluation of economic and monetary conditions is much more effective compared to the individual use of interest rate or exchange rate as an independent variable.

\section{References}

Airado M., Derviş K., Gros, D., Özatay, F., Bayar, F., \& Işık, Y. (2004). Stabilizing the Stabilisation. EU-Turkey Working Papers, No: 7, Center for European Policy Studies.

Batini, N., \& Turnbull, K. (2002). A dynamic monetary condition index for the UK. Journal of Policy Modelling 24, 257-281. Discussion Paper, No. 1, Bank of England. http://dx.doi.org/10.5296/jbls.v6i2.7119 
Bayangos, V. (2000). A real monetary conditions index for the Philippines: is it useful? Working Paper ORPAS-Institute of Social Studies, No. 309.

Bianchi, J., \& Mendoza, E. (2011). Over borrowing, Financial Crises and 'Macro prudential' Policy. IMF Working Paper No. 11(24).

Brash, D. (1997). Exchange Rates, Export Prices, and the Reserve Bank's Monetary Conditions Index. RBNZ speech, 22 August.

Calvo, G., \& Mishkin F.S. (2003). The Mirage of Exchange Rate Regimes for Emerging Market Countries. NBER Working Paper, No. 9808.

Duguay, P. (1994). Empirical Evidence on the Strength of the Monetary Transmission Mechanism in Canada: An Aggregate Approach. Journal of Monetary Economics, 33, 39-61. http://dx.doi.org/10.1016/0304-3932(94)90013-2

Eika, K. H., Ericsson, N. R., \& Nymoen, R. (1996). Hazards in implementing a monetary conditions index. Oxford Bulletin of Economics and Statistics, 58, 765-790. http://dx.doi.org/10.1111/j.1468-0084.1996.mp58004009.x

Ericsson, N. R., Jansen, E. S., Kerbeshian, N. A., \& Nymoen, R. (1998). Interpreting a Monetary Condition Index in Economic Policy. In BIS Conference Papers, No. 6.

Freedman, C. (1995). The Role of Monetary Conditions and the Monetary Conditions Index in the Conduct of Policy. Bank of Canada Review Autumn, 53-59.

Frochen, P. (1996). Monetary Conditions Indices. Banque de France Bulletin Digest, No. 31, July.

Gan, P. T. (2008). Estimating Monetary Policy Rules: An Optimal Monetary Conditions Index for Malaysia. International Research Journal of Finance and Economics ISSN 1450-2887 Issue 14.

Gerlach, S., \& Smets, F. (2000). MCIs and Monetary Policy. European Economic Review, 44, 1677-1700. http://dx.doi.org/10.1016/S0014-2921(99)00013-6

Goodhart, C. A. E. (2000). Can Central Banking Survive the IT Revolution? International Finance, 3(2), 189-209. http://dx.doi.org/10.1111/1468-2362.00048

Goodhart, C., \& Hofmann, B. (2001). Asset Prices, Financial Conditions, and the Transmission of Monetary Policy. Conference on 'Asset Prices, Exchange Rates, and Monetary Policy', Stanford University, March 2-3.

Grande, G. (1997). Properties of the monetary conditions index. Temi de discussione No. 324, Banca d'Italia.

Hataiseree, R. (1998). Monetary Conditions and Monetary Policy in Small Open Economies: Empirical Results for Thailand under Floating Exchange Rate Regime. Paper Presented During the International Conference on A Macroeconomic Core of An Open Economy for Progressive Industrialization and Development in Asia in the New Millennium, Bangkok, 
Thailand, 16-18 December.

Hyder, Z., \& Khan, M. M. (2006). Monetary Conditions Index for Pakistan. State Bank of Pakistan Working Paper No. 11/06, May.

Jeanne, O., \& Korinek, A. (2010). Managing Credit Booms and Busts: A Pigouvian Taxation Approach. Working Paper, University of Maryland and Johns Hopkins University.

Jore, A. S. (1994). Beregning av en indikator for pengepolitikken. Calculation of an Indicator for Monetary Policy, Penger og Kreditt, 94 (2).

Kara, A. H. (2012). Monetary Policy in Turkey After the Global Crisis. T.C.M.B Working Paper No. 12/17.

Kaytanc1, B. G. (2008). Para Politikası Kurallarının Teorik Analizi: Bazı Basit Kuralların İncelenmesi. Eskişehir Osmangazi Üniversitesi İIBF Dergisi, 11-25.

Kennedy, N., \& Riet, A. V. (1995). A Monetary Conditions Index for the Major EU Countries: A Preliminary Investigation. European Monetary Institute - MESD, Mimeo, November.

Kesriyeli M., \& Koçaker İ.İ. (1999). Monetary Conditions Index: A Monetary Policy Indicator for Turkey. Discussion Paper No: 9908, Ankara: Central Bank of Republic of Turkey.

Knedlik, T. (2006). Estimating Monetary Policy Rules for South Africa. South African Journal of Economics, 74(4), 629-641. http://dx.doi.org/10.1111/j.1813-6982.2006.00091.x

Korhonen, L. (2002). Selected Aspects of Monetary Integration. Bank of Finland Institute for Economies in Transition, BOFIT

Mayes, D., \& Viren, M. (2001). Financial Conditions Indexes. Bank of Finland Discussion Papers, No. 17.

Mayes, D. G., \& Viren, M. (1998). The Exchange Rate and Monetary Conditions in thr Euro Area. Bank of Finland Discussion Paper 27/98.

Nadal-De Simone, F., Dennis R., \& Redward, P. (1996). A Monetary Conditions Index for New Zealand. Reserve Bank of New Zealand Discussion Paper Series No. G96/2, July.

Siklos, P. L. (2002). Is the MCI a Useful Signal of Monetary Policy Conditions? An Empirical Investigation. International $\quad$ Finance, 3(3), 413-437. http://dx.doi.org/10.1111/1468-2362.00059

Stevens, G. R. (1998). Pitfalls in the Use of Monetary Conditions Indexes, Reserve Bank of Australia Bulletin, 34-43.

Svensson, L. E. O. (1998). Open-economy inflation targeting. Sveriges Riksbank Working Paper Series, 52.

Tarı, R., \& Bozkurt, H. (2006). Türkiye'de İstikrarsız Büyümenin Var Modelleri ile Analizi (1991:1-2004:3). Ekonometri ve Istatistik Say1: 4. 


\section{Copyright Disclaimer}

Copyright for this article is retained by the author(s), with first publication rights granted to the journal.

This is an open-access article distributed under the terms and conditions of the Creative Commons Attribution license (http://creativecommons.org/licenses/by/3.0/). 